\section{Educated Folly About Animal Minds and Animal Suffering}

\author{
Willem A. Landman \\ University of the Western Cape \\ South Africa
}

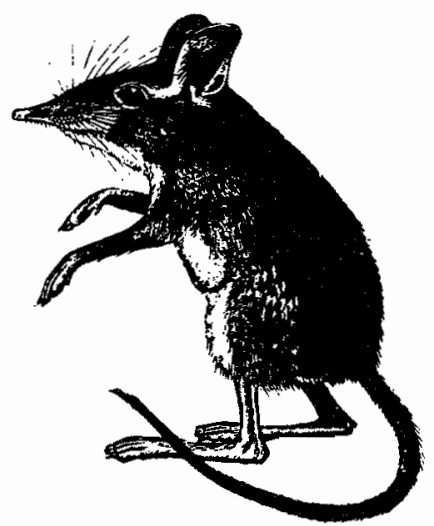

Answer me, mechanist, has Nature arranged all the springs of feeling in this animal to the end that he might not feel? Has he nerves that he may be incapable of suffering?

Voltaire (1694-1778)

\section{Introduction}

In the 1600 s physiologists were beginning to understand the functioning of the major organs of the body and the circulation of the blood. James Rachels tells us how these rapid and exciting advances were achieved by experimental procedures which subjected animals to excruciating tortures: "Dogs, for example, would be restrained by nailing their paws to boards, and then would be cut open so that the working of their innards could be observed. This was long before the development of anaesthetics, and the dogs' vocal cords would sometimes be cut so that their shrieks would not disturb the anatomists."1

Many thought that nonhuman animals (hereafter simply 'animals') did not deserve any sympathy because traditional morality, grounded in Aristotle and Aquinas, made typically human rationality the criterion of moral

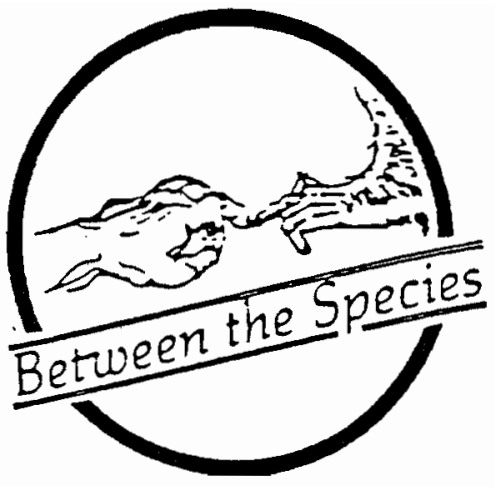

standing. The capacity to experience pain was not sufficient to confer moral standing. But should one nevertheless have had doubts about animals' cries of agony and writhing in pain on the experimenters' boards, there was always Descartes (1596-1650) to comfort one. He argued that animals only had bodies but no minds. They were machines without conscious mental states and incapable even of feeling pain. Humans, however, comprised two separate entities, not only a machine-like body but also an immaterial mind, and were therefore capable of thought and feeling.

Today a Cartesian view of animals as feelingless automata might seem completely counter-intuitive or contrary to common sense. But why would we, who have much the same physiological evidence for animal pain as our seventeenth-century predecessors, hold more humane views? First, between about 1500 and 1800 an alternative, more humane, tradition to that of Aristotelian-Thomian rationality and the Cartesian machine model of animals emerged in England and parts of western Europe among lay people and scientists alike. So it would be wrong to think that our modern sensibilities towards animals and the natural world had no historical roots in the very time that the tradition of typically human rationality and the machine model were at their height. ${ }^{2}$ Second, between Descartes and us came Darwin (1809-1882) who lowered humans from their pedestal of uniqueness and dignity and demonstrated

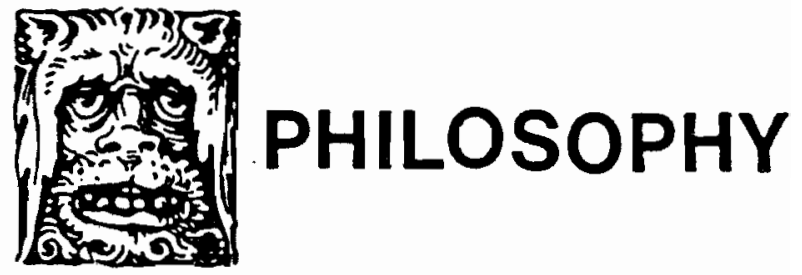


the continuity between humans and animals. ${ }^{3}$ Thus, since the 1850 s our knowledge of animals certainly increased, but far more significant was that all this old and new knowledge could now be located coherently in the context of a background theory of evolution. A rigid divide between, on the one hand, feeling and rational humans and, on the other, feelingless and nonrational animals became utterly implausible.

Still, even after Darwin science has often ignored or denied animal consciousness, especially in the heyday of behaviorism-a new Cartesianism-and logical positivism. ${ }^{4}$ Consciousness remains an embarrassment to biologists because of the success of neurophysiology in explaining behavior in terms of the physical activity of brain cells which appears to leave no useful function for conscious feelings. ${ }^{5}$ Behaviorist psychology aside, cognitive psychologists too are suspicious of animal consciousness, even when they recognize that it must be assumed to explain all sorts of complex animal behavior, and in fact turn out to be methodological behaviorists. ${ }^{6}$

But what about the philosophers? They also have contemporary neo-Cartesians among their ranks. One of them is Peter Carruthers, professor of philosophy at the University of Sheffield. In 1992 Carruthers published a book entitled The Animals Issue: Moral Theory in Practice. Having assumed that animals have conscious mental states for the sake of the argument in the preceding chapters of his book, Carruthers argues in the final chapter that animals are not deserving of our sympathy because all their mental states-experiences (including pain), desires, beliefs, and thinking-are non-conscious. Animals have again become Cartesian machines. Like the Port Royal followers of Descartes one could, on Carruthers's view, torture animals with the confident conviction that their cries of agony were comparable to the noises from machinery. ${ }^{7}$ Or, less dramatically, the family veterinarian, who advises a dog owner that the paramount consideration in the decision to euthanize or not is the dog's suffering, is simply the latter-day equivalent of a flat-earther, both holding irrational beliefs.

In this paper I wish to set out and assess critically Carruthers's argument.

\section{A philosophical argument against animal consciousness and moral standing}

Carruthers believes that animals are not appropriate objects of moral concern that make claims upon our sympathy. His argument for this conclusion can be summarized as follows:

P1: A mental state (such as an experience, including pain, a desire, belief, or thought) is either conscious or non-conscious.

P2: A mental state is conscious if it can be consciously thought about, that is, consciousness that one has a particular mental state is a necessary condition for that mental state being conscious as opposed to non-conscious.

P3: Human beings, but not animals, have the ability consciously to think about their mental states.

C1/P4: Human beings have non-conscious as well as conscious mental states, but animals only have non-conscious mental states.

P5: Having the capacity for conscious mental states, such as the capacity for conscious experience of pain, is a necessary condition for being an object of moral concern that makes claims upon our sympathy.

C2: Animals are not objects of moral concern that make claims upon our sympathy.

This argument is valid, but I believe that $\mathrm{C} 2$, the main conclusion, is false and that the argument is unsound. In support of this view I shall analyze critically each of the five premises on which $\mathrm{C} 2$ rests. ${ }^{8}$

But before I do this I wish to make a general comment about the kind of argument that Carruthers puts forward. It is an argument that draws a moral conclusion from facts about mental states. I believe that this is correct. Intrinsic moral value is affirmative value assigned by valuers (the sources of value) to certain things (the loci of value) in virtue of their possessing specific kinds of characteristics. More specifically, mental states, which are objective features of some living things, ground intrinsic value. Put differently, living things with mental-state interests, in the sense that certain things matter to them subjectively or experientially, have moral standing or are objects of direct or non-instrumental moral concern which makes them direct beneficiaries of moral obligations. I believe that this is neither a case of deriving an 'ought' from an 
'is' contrary to Hume's dictum, nor an instance of Moore's "naturalistic fallacy." This is so because the relationship between fact and value in this kind of argument is neither one of logical entailment of one statement by others, nor one of defining ethics in naturalistic terms, but rather one in which factual beliefs stand in a relationship of support to a moral belief as conclusion. ${ }^{9}$

\section{The distinction between conscious and non- conscious mental states}

In P1 Carruthers ${ }^{10}$ draws a distinction between conscious and non-conscious mental states. Any human mental state - an experience, desire, belief, or thoughtmust be either conscious or non-conscious. Beliefs and desires are either activated or dormant, and if they are activated they are either conscious or non-conscious. ${ }^{11}$ Non-conscious experiences, for example, involve brain functioning, cognitive processing and behavior control but no conscious awareness. ${ }^{12}$ To talk of experiences that are non-conscious is a strange terminological usage since we usually link experience logically with feeling or consider experience to be conscious by definition. But, as Carruthers recognizes, one could simply change his terminology to fit this ordinary usage, in which case some cognitive processing and behavior control would involve experiences (which are by definition conscious) while others would not. ${ }^{13}$

Examples of non-conscious experiences in humans are the following: first, driving a car on a well-known route without being consciously aware that one is doing so while one's conscious attention is directed elsewhere; second, washing up and packing away dishes while one is totally absorbed by music that one has put on; and third, the phenomenon of blindsight where people who have suffered lesions of the striate or visual cortex may lose all conscious experience in an area of their visual field while retaining the ability to describe objects presented to them in that area. ${ }^{14}$

Carruthers next gives an account of the nature of the distinction between conscious and non-conscious mental states in $\mathrm{P} 2 .{ }^{15}$ A mental state is conscious if it can be consciously thought about. The capacity for consciousness that one has an experience is a necessary condition for having a conscious experience. If I can think to myself that $X$ in appropriate circumstances, then belief $X$ is conscious. What I can think about is equivalent to what I can think to myself. This analysis is based on that of Daniel Dennett, for whom conscious experiences are those that are available for the subject to report. Carruthers modifies Dennett by defining consciousness not by its relation to speech production, but rather by its relation to a faculty of thinking. The ability to speak a natural language is however for Carruthers only contingently connected with the possession of conscious mental states.

I wish to make two critical comments about P2. First, Carruthers gives an intellectualized or reflexive account of the consciousness of mental states by identifying the ability to be conscious with the ability to have thoughts. But why must a simple experience of an external phenomenon, or a feeling of warmth or cold, be available for being thought about in order to qualify as a conscious experience? Carruthers's account equates consciousness not only with self-consciousness but with self-consciousness of a certain kind, namely, reflective self-consciousness. Only if one can think about one's mental states are those mental states conscious, and thinking about an experience is a reflectively selfconscious activity. Again, why must an experience be available for being thought about to be perceptually conscious as opposed to being non-conscious? Surely a conscious experience could simply be one that is immediately present to the mind. There is another kind of self-consciousness which is less intellectual than reflective self-consciousness and which does appear to be connected with consciousness or awareness, namely, self-consciousness or self-awareness in the sense of having a concept of self, of having a sense of self as distinct from the world, or of knowing the difference between what happens to one and what does not. ${ }^{16} \mathrm{An}$ ability to recognize dangers and threats to oneself is evidence of this kind of minimal or rudimentary selfconsciousness. ${ }^{17}$

Second, if language is not a necessary condition for consciousness, then it is not clear exactly why it is contingently the case that languageless beings are not conscious while only beings with the ability to speak a natural language are conscious. This case needs to be argued. Carruthers promises to do this in a forthcoming book. ${ }^{18}$ Presumably he will then have to show that language-using creatures have a Chomskian innate ability to speak a natural language that is made possible by innate factors which are the very same factors that make consciousness possible. But even if this were the case, it could be argued that "understanding of reference and meaning requires some non-linguistic comprehension of 
the linkage between sign and what is signified (such as ostension) prior to the acquisition of language; otherwise the entire process would never get off the ground. In short, language requires a peg of non-linguistic experience on which to be hung." 19

\section{Self-consciousness in animals}

In P3 Carruthers makes two factual claims. First, humans have the ability to think consciously about their mental states. Second, animals lack this ability. I shall discuss the latter claim in this paragraph and the former in paragraph 5 .

Do we have evidence that animals can think consciously about their own mental states? Carruthers believes that it follows with very little further argument that animal experiences are non-conscious. ${ }^{20} \mathrm{He}$ believes it unlikely that birds, mice, dogs, cats, sheep, cattle, pigs, or chickens might be thinking things consciously to themselves, in which case the experiences of all these creatures are non-conscious on his analysis. Carruthers makes a little more effort investigating the possibility that higher primates, such as chimpanzees, have conscious mental states. ${ }^{21}$ More specifically, he asks whether chimpanzees can think about their own thoughts. Having considered one example, namely, that of a chimpanzee gathering eighteen pieces of food from a field where he had previously observed the food being hidden in various places, Carruthers concludes that although the chimpanzee has a cognitive map of the field, there is not a shred of evidence to suggest that he is capable of thinking about his thinking. Carruthers then suggests "that human beings are unique amongst members of the animal kingdom in possessing conscious mental states." 22

It is clear that Carruthers dismisses the possibility of animals having the ability to think about their mental states in a rather cavalier a priori manner. First, he declines to consider empirical studies of non-primates like cats, dogs, and the like. Second, he considers only a single case study of higher primates. Third, he considers only a single species of higher primates, namely chimpanzees (and possibly only a single chimpanzee, but that is not clear). Fourth, he considers only a single piece of chimpanzee behavior since he is confident that " $(h)$ ere is about the most intelligent thing that I know of that a chimpanzee can do." ${ }^{23}$ Fifth, he considers only evidence for thinking about thinking and not for less intellectual cognitive abilities such as thinking about an experience.

What should Carruthers have done? Clearly, he should at least have considered the different kinds of evidence for animals' ability to be self-conscious in both the reflective sense and in the sense of having a concept of self. The kinds of evidence I have in mind are animal communication, language-using ability in animals, animals' ability to recognize mirror-images of themselves, and animal behavior in experimental conditions as well as in field research. Weighing such evidence is a task in its own right. My point is simply that unless this is done we have little reason to accept Carruthers's a priori argument. Only if Carruthers insists that thoughts be expressible in human language, which he does not, would it be implausible that animals can think things consciously. I shall argue (in paragraph 6) that we have overwhelming reason to believe that animals are conscious, understood in a way that does not collapse consciousness into reflective self-consciousness.

It is instructive to note that Rosemary Rodd, who is both a biologist and philosopher, puts forward five kinds of consideration in favor of self-consciousness in animals, a term which she defines as the ability to form mental concepts about the self and/or to reflect about one's feelings. ${ }^{24}$ First, recognition of external or mirror images of oneself, as by chimpanzees, is evidence for a sophisticated ability to think about the self from 'outside' or to displace the concept of self beyond the physical body. Second, it is reasonable to believe that members of several primate species other than chimpanzees possess some ability to have ideas about their own knowledge because they appear to have ideas about the knowledge which is available to others or about others' attitudes and personalities, or they appear to form hypotheses about the behavior of others and about the relationships between them and others. Third, animals must constantly receive information about their bodies, and to assume that they can have no concepts about this seems implausible since information about the self as physical entity must have at least as much survival value as information about the external environment. Fourth, the imitation of voluntary behavior of others, such as an orphaned kitten reared with and imitating dogs, is one kind of behavior which seems to be explicable only in terms of some degree of consciousness of self. Fifth, self-consciousness seems to evolve gradually, starting from simple beginnings, 
and probably develops gradually as we grow up. And if self-consciousness is a matter of degree, then a sudden break, rather than a continuum, between humans and animals in respect of the possession of self-consciousness is implausible.

\section{Non-conscious humans}

The second factual claim made in $\mathrm{P} 3$ is that humans have the ability to think consciously about their mental states. Carruthers suggests "that human beings are unique amongst members of the animal kingdom in possessing conscious mental states." $25 \mathrm{He}$ should however have qualified the term 'human beings' with 'some' or 'most'. On his analysis the 'pain' of certain humans-like young babies, severely mentally defective people, and the very senile-must be a nonconscious mental state just like that of animals because they cannot think about it.

Earlier in his book, when he still works on the provisional assumption that animals have conscious mental states, Carruthers uses two moral arguments in support of an extension of contractualism (the moral theory which he favors over utilitarianism) so that it would include in the class of holders of direct moral rights human beings who are not rational agents or rational contractors since they are not normal, adult human beings. ${ }^{26}$ Now it seems to me possible that someone could attempt to use these arguments, not so much to show that non-rational humans are holders of moral rights while animals are not, but to show that humans who lack the capacity for conscious experience on Carruthers's analysis (being unable to think about their mental states) should be treated as if they were conscious while animals should not be so treated. Given this possibility, I wish to show that these moral arguments fail because they have false empirical premises.

First, the slippery slope argument states that the denial of moral rights to human beings on the ground that they are not rational agents may land us on a slippery slope leading to all kinds of barbarism against those humans who are rational agents. This argument fails because there is no a priori reason why excluding animals from direct moral consideration would not likewise throw one on a slippery slope.

Second, according to the social stability argument, a rule that withholds moral standing from non-rational human beings is likely to produce social instability because many people would find themselves incapable of living in compliance with it. This argument fails because it could at most only be contingently so that excluding non-rational human beings from direct moral considerability would lead to social instability. There have been highly civilized and stable societies which practised infanticide or euthanasia of the aged. Conversely, social stability need not be confined to rules about human beings, and in future-if it is not already the case-there might very well be societies in which the denial of moral standing to animals, or senseless destruction of the natural environment, would lead to social instability.

Elsewhere Carruthers presents a third moral argument for why non-rational humans should be included in the sphere of direct moral concern. ${ }^{27}$ Unlike animals, non-rational humans share human form and many human patterns of behavior with those humans who are rational agents. And since we have a natural impulse of sympathy for the sufferings of all who share human form, indifference to the suffering of a nonrational human is wrong because of what it reveals about one's character. Apart from the notoriously problematic issue of what is natural and what is acquired in human nature, I cannot think of any reason why indifference to the suffering of an animal could not also be wrong because it reveals a bad character. Surely, higher primates, for example, share a considerable part of human form and also many typically human patterns of behavior. Why then would torturing them not reveal something about lack of sensitivity which is part of what it means to have a bad character?

I conclude that if these three moral arguments fail, as I think they do, to establish adequate grounds for including non-rational human beings in the class of holders of moral rights while excluding animals, then they would likewise fail were they to be used in an attempt to include, on empirical and moral grounds, non-conscious human beings in the class of conscious human beings while excluding animals.

\section{Analogy, evolutionary theory, and animal consciousness}

There is a very strong argument for animal consciousness. It is a common-sense empirical argument by analogy from human behavior issuing from conscious mental states to animal behavior similarly issuing from conscious mental states. The analogy is considerably strengthened by a mass of 
scientific fact about neurophysiological and neurochemical similarities between humans and animals. And when this analogical reasoning is located in the context of the theory of evolution-which postulates physiological and anatomical continuity, or evolutionary kinship, between humans and animals-an opposing argument that denies any animal consciousness faces formidable odds.

Before I elaborate on this analogical argument, let us first consider what Carruthers is able to muster in its place for his conclusion that animals are non-conscious. Ultimately one has to weigh whether Carruthers's mechanistic explanation of animal behavior is better than the analogical argument which claims that consciousness plays a causal role in, or is implicated in the explanation of, some animal behavior.

In P4 Carruthers states that whereas human beings have non-conscious as well as conscious mental states, animals have only non-conscious mental states. We saw (in paragraph 3) that he cites three examples of nonconscious experiences in humans. Now, presumably, these examples illustrate the non-conscious nature of all animal mental life from which issues animal behavior and in terms of which animal behavior is to be explained. But there are problems with regarding these examples as exemplars in this way. First, the examples of driving a car and washing dishes without being consciously aware of doing so involve complex habitual actions without being aware of them. However, we were consciously aware of these actions in the first place and this made it possible to learn how to perform them and to concentrate on, or to be distracted by, something else while performing them. ${ }^{28}$ Second, the example of blindsight is of people who previously had the ability to see, and Evelyn Pluhar argues that it makes no sense in a context where no conscious experience has ever occurred. ${ }^{29}$ Blindsight, it will be recalled, is the ability to catch balls or identify objects without having any conscious experience of seeing because of lesions in the visual cortex. In this regard Bernard Rollin remarks as follows about Gallup's account of animal consciousness which also makes use of the phenomenon of blindsight: "Why accept a rare, flukish oddity like blind sight as a metaphor for the multitude of apparently conscious animal behaviors? There is a huge functional discrepancy between blind sight and a great deal of, if not most, animal behavior." 30

So, Carruthers asks us to believe that animals are non-conscious machines on the basis of these problematic examples. But he fails to provide us with an explanation of what it would be like to interact in a complex way with the environment, perform tasks, adapt, learn, and the like without any conscious experience at all or ever feeling anything. ${ }^{31}$

Is all animal behavior simply reflex or instinct? Are animals automata? Is animal behavior better explained in terms of the workings of machines or 'hard-wired' mechanical devices, albeit with the input of nonconscious mental states, than in terms of conscious mental states, that is, mental contents which are immediately present to their minds? Does no animal behavior issue from conscious mental states, such as conscious experiences, desires, beliefs, or thoughts?

There is a very strong analogical argument which concludes that the best explanation for complex, adaptive, flexible animal behavior is that it issues from consciousness. Before expanding on this analogy, we need to ask why Carruthers's implied mechanistic analogy between animals and machines breaks down. The obvious answer is that there is no strong physical analogy between animals and machines. Machines are artifacts, animal species are natural kinds. Machines contrast with the structural and functional continuity between humans and animals. The intentionality, plasticity, and flexibility of the behavior of machines, which are suggestive of choice, are only apparent since they are in reality parasitic on, or derivative from, such descriptions which are given of human behavior which issues from consciousness and choice. ${ }^{32}$

One could of course make the machine model of animal behavior more sophisticated by using a modern computer rather than a clock, as Descartes did, as an example of a machine. The non-conscious mental states of animals would then be analogous to software and animal brains analogous to hardware. Animals conceived as computers would be non-conscious in the same way as the most advanced artificial intelligence has no conscious mental states. Computer-like manipulation by animals of data in terms of logical or formal sequences would have syntax but would lack any semantics or referential meaning for the animals themselves. The semantics of a computer program is fully conditional upon the intentionality of the programmer or other human beings. A computer can forecast the weather or calculate the inflation rate but only in a purely logical or formal way without knowing what the content of that activity is or what in the world it is about. 
What reason do we have then for rejecting a machine or computer model of animal behavior in favor of the belief that conscious mental states mediate some animal behavior? Or are conscious animal mental states redundant theoretical postulates devoid of explanatory value? After all, conscious animal mental states are vague and cannot be directly known, and animal minds are mysterious and unfathomable to us. A quick response would be that conscious human mental states could likewise be vague and incapable of being known directly notwithstanding human beings' capacity for natural language. The mind of a Serb ethnic cleanser, raping a mother and gouging her son's eyes, could likewise be incomprehensible. Also, we have very good reason to accept the causal or explanatory role of inferred conscious mental entities in much the same way as we do with inferred physical entities such as electron shells in the minutest constituents of the physical world and quarks in the enormity of outer space. ${ }^{33}$

But there is a better response. There is a widespread common-sense belief that animals have conscious mental states which play a causal role in their behavior and serve as better explanations of their behavior in many specific instances than reductionist accounts which exclude explanatory mental categories. Our everyday speech and the way in which we treat animals that we know reflect this common-sense belief. We make an empirical inference or postulation by analogy from the complex causal connection between our own mental states, such as desires and beliefs, and our own actions to the existence of animal mental states which play a causal and explanatory role in animal behavior. So, our common-sense understanding across cultures analogically ascribes mental properties to animals. Why is this? Rodd suggests that the "central reason why we believe that other people and animals have experience is that $w e$ are conscious and we have an innate tendency to ascribe consciousness to entities which act in ways which we recognize as signs of sensation." 34 We know that we can find out what animals prefer if we present them with a choice of alternatives. ${ }^{35}$ Our common-sense knowledge of animal behavior is the cumulative wisdom of centuries of sharing this world with them.

In essence, we believe that the complexity, plasticity, adaptability or flexibility of animal behavior in situations of choice give us good inductive reason to believe that animals have mental states which mediate their behavior analogous to human mental states mediating similar human behavior in similar circumstances. This commonsensical analogical inference is considerably strengthened by growth in scientific knowledge, not only of animal behavior but also of the similarities between human and animal bodies. Thus, since mind presupposes body, or at least certain bodily structures such as the central nervous system, these similarities make the common-sense analogy all the more plausible, certainly more so than a machine analogy. Bodily similarities involve enzymes and proteins, physiological and anatomical structures, and organic functions. In the next paragraph I shall elaborate on the neurophysiological and neurochemical similarities between humans and animals in respect of feeling pain. Here I am simply stating the elements of the analogy.

Why is this a good analogy? Rollin gives an account of three objective criteria for the ascription of mentation provided by the nineteenth-century Darwinian scientist, George Romanes. ${ }^{36}$ First, the activities must be of a living organism. Second, the activities must be of a kind to suggest the presence of consciousness and choice, two elements which we recognize as distinctive characteristics of mind. Third, another criterion is needed because what seems like intentional or conscious choice may in fact be automatic or reflex action. It is possible that mechanisms of the nervous system could produce, without the mediation or intervention of conscious mental states, highly coordinated and apparently intentional muscular movements. This third criterion then is the ability to adapt to new situations and to learn from experience. Not only 'intelligent' behavior but also mental states like emotions and pain have value since they elicit variable, appropriate behavior, depending on the circumstances. These, then, are three objective methods of determining the presence of subjectivity. Indicators of intentionality, plasticity, flexibility, and choice are objective signs of subjective awareness. Studying animal consciousness means beginning with the facts of our own consciousness and extending them on the basis of analogy.

What is the alternative if one refuses to accept that many of the subjective mental states of humans have analogies in the conscious mental states of animals? It is to accept that-in spite of all the similarities of behavior, structure, function, and the like-of all the animals on the phylogenetic scale, consciousness is only present in humans. Of course it is possible that only human brains have developed the capacity to produce subjective experience over and above non-conscious 
information processing and behavior control, but in the light of the analogical argument for animal mental states, this is an arbitrary assumption. That only the human brain, and no brain of any other species, has precisely the level of development at which consciousness becomes possible seems like an anthropocentric assumption. ${ }^{37}$ It is far more plausible to believe that consciousness in all its manifestations forms a continuum across species lines.

There is, however, one crucial consideration which puts the arbitrariness of an anthropocentric assumption beyond question. If we locate the common-sense understanding of animal consciousness, scientific fact, and the argument from analogy within the context of a background theory, namely, the theory of evolution, we have overwhelming reason to reject a mechanistic model of animal behavior. ${ }^{38}$ The theory of evolution is a well-confirmed, respectable scientific theory of great simplicity and wide explanatory power. It postulates evolutionary continuity or kinship between humans and animals and shatters the traditional divide between the two. Humans are part of the animal kingdom, and precisely the same forces which shape animal nature are at work in the shaping of human nature, even though humans have attained a kind of mental capacity which is a considerable advance upon that of animals. Humans and animals alike are genetically shaped in a complex and slow process of interaction with their ever-changing external environment in such a way that they can best be adapted to survive. The theory of evolution explains biological phenomena, and it tells us why consciousness has survival value. And if having a mind has survival value for humans, then, given the physiological preconditions for mind as well as evolutionary continuity, having a mind would likewise have survival value for animals.

So, common sense, scientific fact, the logic of argument by analogy, and the theory of evolution combine to make the ascription of conscious mental states to animals far more plausible than Carruthers's machine hypothesis. Of course, what I have said is still very general. One would have to look at particular case studies to make specific inferences about particular animal mental states in particular circumstances. But this can be done, and is being done, with varying degrees of success. ${ }^{39}$ Some animals behave in ways that are quite different from the ways in which humans behave in similar circumstances, and there are behavior variations among different kinds of species and among individual members of the same species. Which pet owner cannot tell some tale or another, such as the difference in the ability of individual cats to learn how to use a trap door?

Apart from addressing the last premise in Carruthers's arguments, in the next paragraph I shall move beyond a general assertion of evolutionary continuity of consciousness by looking at the behavior of animals in situations that humans would find painful or stressful and asking whether we have reason to believe that animals actually feel pain or experience distress.

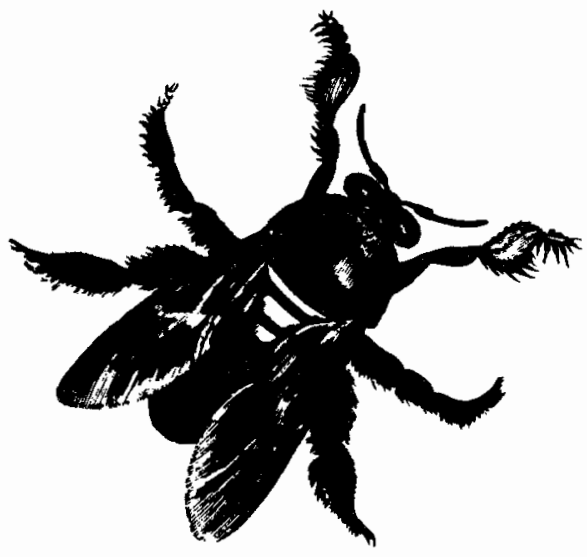

\section{Animal pain, distress, and suffering}

Carruthers's P5 says that having the capacity for conscious mental states, such as the capacity for conscious experience of pain, is a necessary condition for being an object of moral concern that makes claims upon our sympathy. (A sufficient condition of moral standing for him has to be understood in the context of a Rawlsian agreement or contract among rational agents and encompassing only human beings.) The capacity to experience pain could quite rightly be said to be a kind of bottom-line mental capacity for grounding moral standing. But consistently with his denial that animals can have conscious mental states, Carruthers denies that animals can feel pain.

Carruthers claims that pain, like any other mental state, admits of conscious and non-conscious varieties. ${ }^{40}$ He concedes that there are no uncontroversial examples of non-conscious pain in humans which are parallel to our everyday examples of non-conscious visual 
experience. Carruthers then asks whether there are cases of pain parallel to those of blindsight, that is, cases where the full, or nearly full, range of pain-behavior, is displayed without the subject being conscious of or feeling any pain. He concludes that he has no knowledge that such cases have actually occurred, but that the neurophysiology of pain perception suggests that they are in principle possible but then only as a result of surgical intervention. He then considers an imaginary example of someone who is never conscious of any pain in her legs, but who displays much of the normal pain-behavior when she suffers injury in that region. Carruthers concludes that this imaginary case of nonconscious pain, or "of events that otherwise occupy the normal causal role of pain, but which are not available to be thought about consciously and spontaneously by the subject," is (logically and physically) possible.41 Pain, like other mental states, admits of conscious and non-conscious varieties, but since animals are incapable of thinking about their own mental states, their pains must all be non-conscious ones.

There are three ways in which to resist this wildly counter-intuitive conclusion. We have already looked at two of these, namely, a critical analysis of Carruthers's distinction between conscious and nonconscious mental states (paragraph 3 ), and an empirical exploration of the possibility that animals have conscious mental states even on his flawed analysis of this distinction (paragraph 4). Here I wish to explore a third way, that is, the neurophysiology and neurochemistry of pain (and related notions) in humans and animals. This is an area of investigation which Carruthers simply disregards-as, unfortunately, do too many philosophers - in his attempt to make a case for the non-existence of animal pain and suffering. He prefers to use an imaginary example of nonconscious pain (which, as he himself admits, is not a reality like blindsight) and to rely on an a priori analysis in which he intellectualizes suffering. Against Carruthers one could insist that the elements for a strong analogical argument for animal pain and suffering are provided by scientific knowledge about the bodily prerequisites for pain in humans and animals, coupled with evidence from observation of pain-like behavior in humans and animals in the appropriate circumstances. To deny that animals can feel pain, in spite of all the similarities between human and animal bodies and behavior, is extremely odd, if not bizarre, as the quotation from Voltaire under the title of this paper suggests.
What do we understand by the concept of pain? A common-sense understanding of pain necessarily includes a sensation or feeling that is intrinsically unpleasant. Pain, say David DeGrazia and Andrew N. Rowan, is either a particular kind of unpleasant sensation-identified by a particular phenomenological quality - or is a particular qualitative range of unpleasant sensations. ${ }^{42}$ Pain is by definition experienced so that expressions such as 'unexperienced pain' or 'unfelt pain' are self-contradictory. Similarly, according to common sense and ordinary language, Carruthers's notion of nonconscious pain is self-contradictory.

Pain is, however, more than a sensation or feeling. Scientific work suggests that the human model of pain has three components, each of which provides an area of evidence for animal pain..$^{43}$ The first component of pain is nociception or the detection of noxious stimuli which does not involve any conscious awareness. ${ }^{44}$ Nociception is the detection of (potentially) tissuedamaging stimuli by specialized neural end-organs with accompanying behavioral events, such as the reflexive withdrawal of the affected part of the body from the source of injury. Nociceptors exist in all mammals and birds, and evidence suggests the existence of nociception in all vertebrates and possibly in some invertebrates such as cephalopods, for example, octopi and squids.

The second component of pain is the perception of noxious stimuli. ${ }^{45}$ This is pain as feeling or sensation. One perceives noxious stimuli, but one does not perceive pain because pain is by definition perceived. One has, feels, or experiences pain. Several neuroanatomical aspects of the sensation component of pain are relevant to the question whether animals can feel pain. First, all vertebrates possess the requisite spinal aspects of pain perception, namely, neural connections between peripheral nociceptors and central nervous structures. It is doubtful that insects feel pain because they lack the extensive nervous system processing mechanisms that appear to be necessary for pain, and their behavior, when faced with noxious stimuli, can be explained by the nociceptive reflex. ${ }^{46}$ Second, the thalamus and primary sensory cortex are the supraspinal structures implicated in pain perception, but there is uncertainty about the activity of the cerebral cortex in pain sensation. There are anatomical differences between species in the cerebral cortex, and these may have important implications for pain sensation and emotional response to pain (the third component of 
pain). Similarity of these neural prerequisites for pain permits the possibility of pain sensation in all vertebrates, but there are qualitative and quantitative differences in pain sensation grounded in rapid sensorydiscriminatory ability and in the greater influence of cognition (made possible by the third component of pain). Third, endogenous pain-control or painmodulating mechanisms are constituted by both complex descending pain-control circuits and the opiate system (endogenous opioid peptides, such as endorphins). These mechanisms probably exist in all mammals, and there is even evidence for them in invertebrates such as earthworms. Fourth, there is stressinduced analgesia consisting of an opioid-dependent and a non-opioid system, both of which can be activated by nociceptive stimulation and by various psychological stresses, such as exposure to a novel environment. It involves supra-spinal mechanisms, but available data is limited. In sheep, for example, the non-opioid system predominates.

The third component of pain is motivationalaffective, involving cognitive and emotional capacities. ${ }^{47}$ Noxious stimuli or sensory inputs are not only felt or sensed, but are cognitively evaluated or interpreted and result in emotional behavior or affective response. Hence pain is defined not merely as sensation, but as unpleasant sensation. Both evaluation and behavioral response require a certain level of cognitive ability which in turn is grounded in, or made possible by, the cerebral cortex. The motivational-affective component may assume greater complexity and importance in the pain perception of animals with a developed cerebral cortex. The minimal level of cognitive development for pain perception remains speculative. It is suggested that only the most rudimentary level is required, and on this basis pain is recognized in all vertebrate species.

Given these three components of pain, as well as pain-associated behavior, we have solid grounds for believing that all vertebrate species are capable of pain. This is not the case with imputing the capacity for pain to invertebrates, but evidence of pain-associated behavior in some invertebrates should give one reason to pause. It is not known what the capacity for motivational-affective modulation of pain is in less complex vertebrates such as fish, amphibians and reptiles. In mammals, pain sensation is modulated by emotional and cognitive modalities. Great apes have a level of cognitive development which indicates that cognitive processes are likely to have a greater influence on their experience of pain. Human beings differ from animals in the cognitive modalities of pain perception, cognition being a major determinant of their pain perception. In short, the neurophysiology, neurochemistry, and behavioral repertoire of pain support the thesis that many if not all vertebrates experience pain. ${ }^{48}$

Pain and suffering are related but not identical concepts. I may be in pain (that is, have a nociceptive response to a knife thrust into my arm, have a hurtful sensation, and have a cognitive and emotional response to both this action and hurtful sensation) without suffering. Suffering, unlike pain, is not a sensation and is not locatable in particular body parts. ${ }^{49}$ When does the experience of pain involve suffering? Suffering could be defined as the unpleasant emotional response to more than minimal pain or distress. ${ }^{50}$ Emotions are thus implicated in pain as well as suffering, but the emotion induced by suffering is the result of pain with a raised level of intensity or duration.

Suffering is, however, not only caused by pain but also by distress. Distress is a state in which a human or animal is unable to adapt to an altered environment or to altered internal stimuli. ${ }^{51}$ Distress can take different forms, such as anxiety, fear, or boredom. Anxiety, for example, can be defined as "an emotional responsetypically unpleasant, typically involving heightened arousal and attentiveness to the environment, and typically inhibiting action-to the perception of a threat to one's well-being or to one's ego (sense of self)." 52 It is not clear whether anxiety is, like pain, always felt, but in the context of animal welfare felt anxiety is of most interest. In this definition 'perception' of threat allows for cases where no real threat exists, and threat to 'ego' accommodates typically human cases. Anxiety causes people to feel more pain given a particular stimulus, ${ }^{53}$ the experience of pain can be attenuated or accentuated by emotion. ${ }^{54}$ Clearly, then, the concepts of pain, distress (anxiety and the like), and suffering are located in the same conceptual field.

Are animals capable of experiencing anxiety? There are good reasons, based on analogical inference from observable facts, for believing that they do. Anxiety in humans as well as inferred 'anxious' states in animals are accompanied by typical anxious behavior, are modulated in the same way by drugs, and produce neurophysiological and neurochemical changes. Symptoms characteristic of states of anxiety, 
which are observed in both humans and animals in circumstances that cause human anxiety, are motor tension (shakiness, etc.), autonomic hyperactivity (sweating, pounding heart, etc.), apprehensive expectation (inhibition of behavioral repertoire in novel situations), and hyperattentiveness (vigilance and scanning). ${ }^{55}$ Animals have been used in experiments to develop anxiety-relieving drugs for humans. The neurochemical basis of anxiety is the benzodiazepine receptors in the central nervous system in human beings and animals. ${ }^{56}$ Benzodiazepine receptors are present in vertebrate species, including fish, but no significant levels have been detected in invertebrates. ${ }^{57}$ In other words, the physiological basis of anxiety, namely receptor sites for benzodiazepine, exists in all vertebrates. ${ }^{58}$ Studies in monkeys and rats, for example, demonstrate that benzodiazepine receptors are involved in both the affective and physiological manifestations of anxiety in these species, although there are species variations. ${ }^{59}$

Thus, the analogical argument for animal anxiety moves from anxiety in humans, evidenced by human anxious behavior and benzodiazepine receptors, to inferred animal anxiety, evidenced by animal anxious behavior and benzodiazepine receptors. It is an empirical argument from behavioral and neural similarities to conscious mental states. This analogy gives us excellent reason for believing that mental states mediate between the physical or psychological anxietyinducing stimulus and the physiological anxious response, thus rejecting the claim that anxiety (and other forms of distress) in animals is simply a mechanicalphysical matter. ${ }^{60}$

Finally, are animals capable of suffering induced by pain or distress (such as anxiety)? Given that suffering is defined as the unpleasant emotional response to pain or distress, the question of animal suffering raises the question of animal emotion. In the discussion of the three components of pain, I have already suggested that there are behavioral and neural analogies between humans and animals which give us inductive reason to infer animal emotions. Emotions modulate pain and anxious experiences. Since emotion is the affective response to an evaluation and interpretation of sensory inputs from the internal and external environment, evidence of the existence of emotion supports the possibility of pain and anxious experiences. Animals, then, can suffer in the form of having an unpleasant emotional response, and their suffering is caused by pain or distress (such as anxiety) that is more than minimal.

I have merely given a crude outline of conceptual and empirical considerations-both behavioral and anatomical similarity, set in the context of evolutionary kinship-relevant to the possibility of animal pain, distress, and suffering. But it is sufficient to provide adequate prima facie reason to distrust Carruthers's case against (conscious) animal pain, pain for him being an avoidance mechanism without feeling, a case grounded in imaginary examples and a priori argument. Although animals do not have the most sophisticated intellectual abilities, associated with human language, to evaluate and interpret pain, distress or suffering, we have overwhelming scientific evidence to support the widespread commonsensical belief, grounded in the human analogy, that animals do feel pain, are anxious, and do suffer.

\section{Ethics and non-conscious animals}

Carruthers's moral conclusion, $\mathrm{C} 2$, is that animals are not objects of moral concern that make claims on our sympathy. He believes that if he is right about the non-consciousness of animal mental states, "then it ought to be strictly impossible to feel sympathy for animals, once the true nature of their mental contents is properly understood... The truth may be that it is only our imperfect rationality that enables us to feel sympathy for animals at all." 61 This is a far-reaching conclusion, and Carruthers does not shy away from spelling out its consequences: "The most important practical conclusion of this book is that there is no basis for extending moral protection to animals beyond that which is already provided." 62 In particular, there are no good moral grounds for forbidding hunting, factory farming, or laboratory testing on animals. Feelings of sympathy for animals "serve only to divert attention from the claims of those who do have moral standing, namely human beings." 63

Just as key premises in Carruthers's argument are false, $\mathrm{C} 2$ is also false. His moral conclusion is a species of educated folly which deserves to be buried along with its seventeenth-century Cartesian ancestors. From a dubious philosophy of mind he draws a moral conclusion which, if acted upon, would serve to stabilize the status quo. An alternative conclusionsupported by common sense, the logic of analogical reasoning and the theory of evolution-is that sentient 
animals, that is, animals that are capable of pain and suffering, have moral standing and, as such, set limits to our actions in virtue of what they are in themselves. On this alternative conclusion practices like factory farming cause unspeakable suffering. To claim that expending time and energy on this moral issue diverts attention from the needs of human beings is to suggest that one can only properly pay attention to one thing in one's life-plan, or that animal welfare and human welfare are mutually exclusive. These are not the case. Life is indeed too short to pursue all worthwhile causes at once. But one could argue persuasively that domesticated animals are part of human communities and are owed duties of care and gratitude. Regard for animals is not an invention of a decadent moral society, ${ }^{64}$ but is a human moral sense which has deep historical and social roots. ${ }^{65}$ Moreover, vested economic interests, structural political power, and human wickedness are far more fundamental and pervasive causes of a failure to address human suffering than the animal rights (animal welfare; animal protection) movement. But this is another issue.

In conclusion, Carruthers, having argued that animals have only non-conscious mental states, cautions that his argument is controversial and speculative, and that it may well turn out to be unsound. ${ }^{66}$ Consequently, it may be wiser, he says, to continue to respond to animals as if their mental states were conscious ones until a consensus emerges amongst philosophers and psychologists concerning the nature of consciousness, and among ethologists over the cognitive powers of animals. The good news is, however, that consciousness is being regained in both psychology and ethology and that philosophy has long ago dumped logical positivism, the bedfellow of behaviorism, which denies consciousness. A lack of consensus on animal consciousness may very well be explained, in part at least, by the vested interests of researchers who do routine science within a scientific paradigm which denies animals consciousness. ${ }^{67}$ Biology has unfortunately been slow to follow physics in accepting inferred unobservables as respectable explanatory concepts.

\section{Notes}

\footnotetext{
1 James Rachels, Created from Animals: The Moral Implications of Darwinism (Oxford and New York: Oxford University Press, 1991), p. 129
}

2 See Keith Thomas, Man and the Natural World: A History of the Modern Sensibility (New York: Pantheon Books, 1983).

${ }^{3}$ See Rachels, $O p$. cit.

${ }^{4}$ See Bernard E. Rollin, The Unheeded Cry: Animal Consciousness, Animal Pain, and Science (Oxford and New York: Oxford University Press, 1990).

5 See Rosemary Rodd, Biology, Ethics, and Animals (Oxford: Clarendon Press, 1990), p. 42.

${ }^{6}$ See Donald R. Griffin, Animal Minds (Chicago and London: The University of Chicago Press, 1992), pp. vii, 8.

${ }^{7}$ Ibid., p. 248.

8 There are critical discussions by Edward Johnson ["Carruthers on Consciousness and Moral Status," Between the Species, 7(4), 1991, 190-2] and Evelyn B. Pluhar ["Arguing Away Suffering: The Neo-Cartesian Revival," Between the Species, 9(1), 1993, pp. 27-41] of an earlier article by Peter Carruthers ("Brute Experience," The Journal of Philosophy, 86, pp. 258-269), in which he first put forward the argument of the last chapter of his book.

${ }^{9}$ See Rachels, Op. cit., p. 93.

${ }^{10}$ Peter Carruthers, The Animals Issue: Moral Theory in Practice (Cambridge: Cambridge University Press, 1992), p. 171.

${ }^{11}$ Ibid., p. 173.

${ }^{12}$ Loc. cit.

${ }^{13}$ Loc. cit.

14 Ibid., pp. 170-3.

${ }^{15}$ Ibid., pp. 174-183.

${ }^{16}$ See Rollin, Op. cit., p. 140.

${ }^{17}$ Ibid., p. 263.

${ }^{18}$ Carruthers, The Animals Issue, p. 201 note 10.

${ }^{19}$ Rollin, Op. cit., p. 138.

${ }^{20}$ Carruthers, The Animals Issue, p. 184.

${ }^{21}$ Ibid., pp. 184-6.

22 Ibid., p. 186.

${ }^{23}$ Ibid., p. 185.

${ }^{24}$ Rodd, Op. cit., pp. 64-73.

${ }^{25}$ Carruthers, The Animals Issue, p. 186. 
26 Ibid., pp. 110-8.

${ }^{27}$ Ibid., pp. 163-5.

${ }^{28}$ See Pluhar, Op. cit., p. 37

${ }^{29}$ Loc. cit.

${ }^{30}$ Rollin, Op. cit., pp. 263-4.

${ }^{31}$ Pluhar, Op. cit., p. 37.

${ }^{32}$ See Rollin, Op. cit., p. 46.

${ }^{33}$ See Rodd, Op. cit., p.48.

${ }^{34}$ Ibid., p. 62.

35 Ibid., p. 109. See also Mary Stamp Dawkins, "The Scientific Basis for Assessing Suffering in Animals," in In Defence of Animals, edited by Peter Singer (Oxford: Basil Blackwell, 1985), pp. 27-40.

$$
\begin{aligned}
& { }^{36} \text { Rollin, Op. cit., pp. } 42-6 . \\
& { }^{37} \text { Rodd, Op. cit., p. } 59 .
\end{aligned}
$$

${ }^{38}$ Rollin (Op. cit.) locates historically and socially the argument that grounds the continuity of human and animal mentation in the theory of evolution. Rachels $(O p$. cit.) argues elegantly for the importance of Charles Darwin's The Origin of Species for the collapse of the purported factual and moral divide between humans and animals. See Rodd ( $O p$. cit.) for an informed discussion of the relationship between biology and ethics.

${ }^{39}$ Griffin [Op. cit.; The Question of Animal Awareness: Evolutionary Continuity of Mental Experience, revised and expanded edition (Los Altos, CA: William Kaufmann, 1981); and Animal Thinking (Cambridge, MA: Harvard University Press, 1984)] and Dawkins [Op. cit.; Animal Suffering: The Science of Animal Welfare (London and New York: Chapman and Hall, 1980); "From an Animal's Point of View: Motivation, Fitness, and Animal Welfare," in Behavioral and Brain Sciences, 13, pp. 1-9; and Through Our Eyes Only?: The Search for Animal Consciousness (Oxford, New York and Heidelberg: W.H. Freeman, 1993)] present case studies about animal mental capacities and analyses of methods of knowing animal minds. Case studies are woven into Rodd's (Op. cit.) argument. Rollin (Op. cit., p. 271) makes interesting observations about the manner in which Jane Goodall does cognitive ethology through the observation and interpretation of animal behavior. Griffin (Animal Minds) points out that modern ethology need not let consciousness function in explanation of animal behavior and that it could therefore turn out to be a form of methodological behaviorism, a position which he emphatically rejects.

\footnotetext{
${ }^{40}$ Carruthers, The Animals Issue, pp. 187-9.

${ }^{41}$ Ibid., p. 189.
}

42 David DeGrazia and Andrew N. Rowan, "Pain, Suffering, and Anxiety in Animals and Humans," Theoretical Medicine, 12, pp. 193-211.

${ }^{43}$ This conceptual and scientific discussion of pain andrelated notions leans heavily on the commendable work by DeGrazia and Rowan (Op. cit.) and Margaret Rose and David Adams, "Evidence for Pain and Suffering in Other Animals," in Animal Experimentation: The Consensus Changes, edited by Gill Langley (New York: Chapman and Hall, 1989), pp. $42-71$.

${ }^{44}$ See Rose and Adams, Op. cit., pp. 47-9, and DeGrazia and Rowan, Op. cit., pp. 194-6.

${ }^{45}$ See Rose and Adams, Op. cit., pp. 49-55, and DeGrazia and Rowan, Op. cit., pp. 197-9.

${ }^{46}$ See DeGrazia and Rowan, Op. cit., p. 199.

${ }^{47}$ See Rose and Adams, Op. cit., pp. 55-62.

${ }^{48}$ See DeGrazia and Rowan, Op. cit., p. 198.

49 Ibid., p. 200.

50 Ibid., p. 199.

${ }^{51}$ See Rose and Adams, Op. cit., p. 47.

${ }^{52}$ DeGrazia and Rowan, Op. cit., p. 202. Emphasis by DeGrazia and Rowan.

${ }^{53}$ Ibid., p. 201.

${ }^{54}$ See Rose and Adams, Op. cit., p. 56.

${ }^{55}$ See DeGrazia and Rowan, Op. cit., p. 203.

${ }^{56}$ See Rose and Adams, Op. cit., p. 57, and DeGrazia and Rowan, Op. cit., pp. 203-5.

${ }^{57}$ See Rose and Adams, Op. cit., p. 57.

${ }^{58}$ See Rollin, Op. cit., p. 155.

${ }^{59}$ See Rose and Adams, Op. cit., p. 57.

${ }^{60}$ See Rollin, Op. cit., p. 204.

${ }^{61}$ Carruthers, The Animals Issue, p. 192.

62 Ibid., p. 196.

${ }^{63}$ Loc. cit.

${ }^{64}$ See Rodd, Op. cit., p. 239.

${ }^{65}$ See Thomas, Op. cit.

${ }^{66}$ Carruthers, The Animals Issue, pp. 192-3.

${ }^{67}$ See Rollin, Op. cit. 